\title{
A Study to Assess Knowledge and Attitude Regarding Selected Government Health Insurance Schemes among Staff Nurse in Selected Hospitals of Ahmedabad District: A Main Study
}

\author{
Surbhi A. Kaklottar*, Siddaram Sarate \\ Manikaka Topawala Institute of Nursing, CHARUSAT, Changa, Gujarat, India \\ Email: ^kaklottar.surbhi@gmail.com
}

How to cite this paper: Kaklottar, S.A. and Sarate, S. (2019) A Study to Assess Knowledge and Attitude Regarding Selected Government Health Insurance Schemes among Staff Nurse in Selected Hospitals of Ahmedabad District: A Main Study. Open Access Library Journal, 6: e5128.

https://doi.org/10.4236/oalib.1105128

Received: December 20, 2018

Accepted: January 7, 2019

Published: January 10, 2019

Copyright $\odot 2019$ by author(s) and Open Access Library Inc.

This work is licensed under the Creative Commons Attribution International License (CC BY 4.0).

http://creativecommons.org/licenses/by/4.0/

\begin{abstract}
Background: Hospital bills for very small to considerably large ailments are a pain. It's difficult to meet such costs on our own without burning a hole in our savings. Also, with medical costs escalating, some even compromise on quality healthcare, because of affordability. It is then that the importance of health insurance comes into the picture. Objectives of the study: 1) To assess the knowledge regarding selected government health insurance schemes among staff nurses working in selected hospitals of Ahmedabad District. 2) To assess attitude regarding selected government health insurance schemes among staff nurses working in selected hospitals of Ahmedabad District. 3) To find the correlation between knowledge score and attitude score regarding selected government health insurance schemes among staff nurses working in selected hospitals of Ahmedabad District. 4) To find the association between knowledge and attitude score with selected demographic variables. Methodology: The study utilized quantitative research approach with descriptive research design. The sample size was 170 selected using convenient non-probability sampling technique. The data were collected through self-structured questionnaire instrument which is validated by experts. Split half method was computed for finding out the reliability. The data are organized, analyzed and presented by using Karl Pearson's correlation coefficient formula and chi-square test. Major findings and result: The findings revealed that majority of staff nurses had average knowledge $91.18 \%$, and $5.29 \%$ staff nurses had poor knowledge whereas $3.52 \%$ staff nurses had good knowledge. In present study finding reveled that, majority of $87.04 \%$ staff nurses have favorable attitude and $12.94 \%$ staff nurses have unfavorable attitude re-
\end{abstract}


garding MA and MAV Yojana. Computed chi-square value was less than table value at the level of significance indicating no significance association between level of knowledge score and selected socio-demographic variables. Computed chi-square value was less than table value at the level of significance indicating no significance association between level of attitude score and selected socio-demographic variables. Conclusion: Investigators concluded that most of the staff nurses who were participated in the study have average knowledge and favorable attitude regarding selected government health insurance schemes. There is no correlation between knowledge score and attitude score where as there is no association between level of knowledge, level of attitude with socio-demographic variables.

\section{Subject Areas}

Health Policy

\section{Keywords}

Government Health Insurance Schemes, Mukhyamantri Amrutum Yojana, Mukhyamantri Amrutum Vatsalya Yojana, Knowledge, Attitude, Staff nurses

\section{Introduction}

The Government supported insurance schemes are a form of social security in India. These schemes are initiated by the Government to provide protection to certain sections of the population against income losses and can be categorized as social security. In India, Government supported insurance schemes have been initiated in the last decade. A number of schemes that existed earlier have also been modified substantially. While some of these changes have taken place at the State level. More than $72 \%$ of health expenditure in India is financed by individual households at the time of illness through out-of-pocket payments. Only about $3 \%-4 \%$ of Indians are covered under some form of health insurance and four-fifth of the population is still spending out of their own pockets [1].

The World Bank (2002) estimates that one-quarter of all Indians fall into poverty as a direct result of medical expenses in the event of hospitalization. Most studies of health care spending have found that of pocket spending in India is actually progressive. Richer Indians spend marginally more than on health care however because of the lack of resources to pay for health care [2].

In Gujarat State, government focuses on health expenditure more nowadays. For the attainment of the highest level of functioning of physical, mental, social well-being, there is also need of low cost treatment and quality care. Gujarat State had over 31.46 lac BPL families and 18,000 families getting added to the list in the last two years. To address this key vulnerability faced by the BPL population in the Gujarat, Mukhyamantri Amrutam "MA" Yojana was launched by Government of Gujarat. When in the Lower middle class families, critical illness occurs and when such families are not included in the definition of BPL so they 
cannot get free treatment, and they are not able to spend money for critical illness. So, based on feedback from various stakeholders, the Scheme was extended to families of lower income group names as Mukhyamantri Amrutam Vatsalya Yojana [3].

There is major need to be aware of health personnel as well as community also. Through the reviewing of the previous study about the expenditure and different health insurance schemes, there is a major role of health personnel also to be aware about government health insurance schemes.

\section{Methodology}

Quantitative research approach was used in this study. Descriptive research design was used to assess knowledge and attitude regarding selected Government health insurance schemes among staff nurses working in selected hospitals of Ahmedabad District. Permission was obtained from selected hospitals of Ahmedabad district: The sample size was 170 selected by using convenient sampling method. Written consent was obtained from the staff nurses of respective hospital. Data collected by using self-administer structured knowledge questionnaire and Attitude scale. Collected data were tabulated and analyzed. Both descriptive and inferential statistics were used to analyse the data collected. Frequency and percentage distribution were used to analyze the demographic data. Mean median, mode and standard deviation of knowledge and attitude score. Distribution of scores of knowledge (good, average and poor) and attitude (favorable and Unfavorable). Correlation method to find the correlation between total knowledge score and attitude score. Chi-square test and linear regression test are used for association of knowledge score, attitude score with socio-demographic variables.

\section{Result}

Figure 1 shows that; 155 (91.18\%) staff nurses had average knowledge and 9 (5.29\%) staff nurses had poor knowledge whereas only 6 (3.52\%) staff nurses had good knowledge about selected government health insurance schemes.

Table 1 portrays that; 148 (87.06\%) staff nurses had favourable attitude whereas only $22(12.94 \%)$ staff nurses had unfavourable attitude towards selected Government Health Insurance Schemes.

\section{Discussion}

In present study, most of the participants were belonged to female and urban area where as none of the participants has taken any training regarding MA and MAV Yojanas. Most of the participants got information from health care workers about these Yojanas. The mean score of age and work experience is $27.22 \pm$ 4.47 and $4.38 \pm 3.93$. Most of the staff nurses studied GNM. In present study, first objective is about to assess knowledge regarding selected government health insurance scheme among staff nurses who were participated. To assess the 


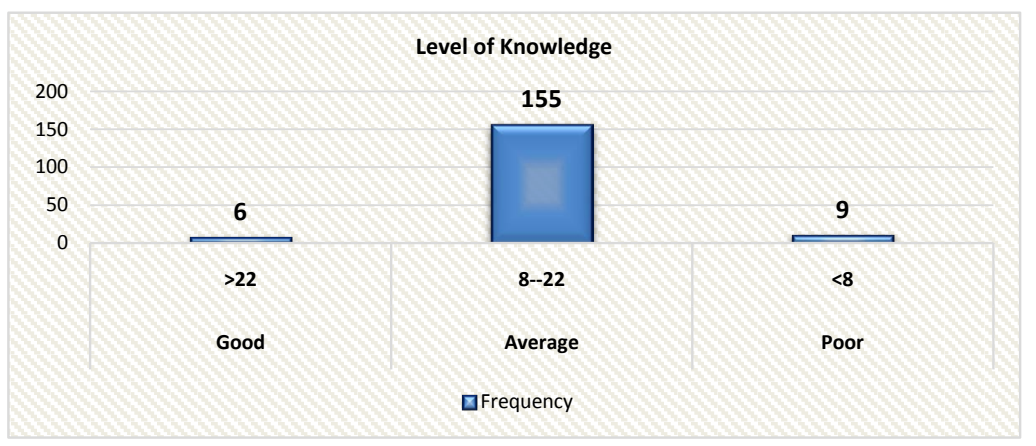

Figure 1. Bar-diagram of frequency and percentage distribution of knowledge Score $\mathrm{N}=170$.

Table 1. frequency and percentage distribution of Attitude score staff nurses regarding selected Government Health Insurance Schemes N = 170 .

\begin{tabular}{cccc}
\hline Attitude & Score & Frequency & Percentage \\
\hline Favourable & $54-90$ & 148 & $87.06 \%$ \\
Unfavourable & $18-54$ & 22 & $12.94 \%$ \\
\hline
\end{tabular}

knowledge among staff nurses structured questionnaire instrument was used. The collected data were analyzed through descriptive and inferential statistics. In present study the analyzed data were interpreted through total knowledge score; mean, median, mode, range and standard deviation of total knowledge score. Mean knowledge score was 14.9 , median was 14 , and mode was 14 . The standard deviation was 3.69 whereas range between highest score and lowest score was 16 . These data were presented in the form of graph.

After calculating the average knowledge score, category for the knowledge score was made by using mean score and standard deviation score. The three categories were made i.e. good knowledge, average knowledge and poor knowledge. 155 (91.18\%) staff nurses had average knowledge and 9 (5.29\%) staff nurses had poor knowledge whereas only $6(3.52 \%)$ staff nurses had good knowledge about selected Government Health Insurance Schemes.

In present study, second objective is about to assess attitude regarding selected government health insurance scheme among staff nurses who were participated. To assess the attitude among staff nurses structured questionnaire instrument was used. The collected data were analyzed through descriptive and inferential statistics. In present study the analyzed data were interpreted through total knowledge score: mean, median, mode, range and standard deviation of total attitude score. Overall mean attitude score is 65.05 , median is 66 , and mode is 66 . The standard deviation is 8.62 whereas range between highest attitude score and lowest attitude score is 43 .

After calculating the average attitude score, category for the attitude score was made by using mean score and standard deviation score. The three categories were made i.e. favorable and unfavorable attitude. 148 (87.06\%) staff nurses had favorable attitude whereas only $22(12.94 \%)$ staff nurses had unfavorable to- 
wards selected Government Health Insurance Schemes.

In present study, there is no significant correlation between attitude score and knowledge score. Correlation score was calculated using Karl Pearson's coefficient correlation method that is $r=0.074$ and the finding shows that there is absolutely no correlation between attitude score knowledge score.

The fourth objective is mainly discussing about if there is any association between knowledge and attitude score with selected socio-demographic variable. The tests used for association were chi-square test and linear regression test. The collected data was interpreted. Computed chi-square value was less than table value at the level of significance indicated no significance association between level of knowledge score and selected socio-demographic variables. Computed chi-square value was less than table value at the level of significance indicated that no significance association between level of attitude score and selected socio-demographic variables.

\section{Conflicts of Interest}

The authors declare no conflicts of interest regarding the publication of this paper.

\section{References}

[1] Choudhury, M. and Srinivasan, R. (2011) A Study on Insurance Schemes of Government of India. National Institute of Public Finance and Policy, New Delhi. https://nipfp.org.in/media/medialibrary/2013/08/insurance_report_final.pdf

[2] Gopi, B.G. (2013) A Study to Assess Knowledge, and Attitude regarding Utilization of Various Health Insurance Schemes among Heads of Families in a Selected Rural Village in Hassan with a View to Prepare a Module on Various Health Insurance Schemes. Karnataka.

http://www.rguhs.ac.in/cdc/onlinecdc/uploads/05_N043_38431.doc

[3] National Health Mission (2018) Mukhymantri Amrutum. Background. https://nrhm.gujarat.gov.in/mukhya-mantri-amrutam.htm 